\title{
CONTROLE INTERNO NO RIO GRANDE DO NORTE: UM ESTUDO NA VISÃO DOS CONTROLLERS MUNICIPAIS
}

\author{
ARAÚJO, Richard Medeiros de ${ }^{1}$ \\ SANTOS, Rodolfo Claudio de ${ }^{2}$ \\ ARAUJO, Maria Arlete Duarte de ${ }^{3}$ \\ DIAS, Thiago Ferreira ${ }^{4}$
}

Recebido em: 2016.10 .29

Aprovado em: 2017.01.03

ISSUE DOI: $10.3738 / 1982.2278 .2143$

\begin{abstract}
RESUMO: Este artigo identifica a percepção dos controladores internos municipais que atuam nos municípios do Estado do Rio Grande do Norte acerca das suas práticas administrativas. Trata-se de uma pesquisa descritiva com abordagem quantitativa com uma=amostra de 36 municípios. Para tratar os dados adotou-se a Análise Exploratória de Dados (AED). Dentre os resultados, vários fatores explicam a percepção dos controladores internos municipais quanto aos aspectos contábeis, de eficiência, controle do ponto de vista do planejamento e controle como forma de assinalar erros. Entre eles, destacamos a falta de membros suficiente para o desempenho das atividades, não compreensão e interesse por parte dos gestores municipais e demais atores e o não cumprimento das orientações e solicitações realizadas pelo controle interno municipal. Conclui-se que essas dificuldades acabam corroborando para o enfraquecimento do 'controle' nos municípios, impedindo um desempenho satisfatório do controle municipal.
\end{abstract}

Palavras-chave: Gestão pública. Controle Interno Municipal. Rio Grande do Norte.

SUMMARY: This article identifies the perception of municipal internal controllers that operate in the municipalities of Rio Grande do Norte state about their administrative practices. This is a descriptive research with a quantitative approach with a sample of 36 municipalities. To process the data it adopted the Exploratory Data Analysis (EDA). Among the results, several factors explain the perception of municipal internal controllers as the accounting aspects, efficiency, control of the point of view of planning and control as a way to point out errors. Among them, we highlight the lack of sufficient members for the performance of activities, not understanding and interest of municipal managers and other actors and failure to follow the guidelines and requests made by the municipal internal control. We conclude that these difficulties end up corroborating the weakening of 'control' in municipalities, preventing a satisfactory performance of municipal control.

Keywords: Public Administration. Municipal Internal Control. Rio Grande do Norte.

\section{INTRODUÇÃO}

O controle interno é considerado um recurso organizacional extremamente salutar para a tomada de decisão, economia, combate à prática de vícios e consolidação do alcance de forma eficiente e eficaz dos serviços inerentes às atividades públicas. Constitui-se um mecanismo para o processo decisório e direcionamento das ações governamentais, via planejamento (MOREIRA, 2004).

A administração pública sem a presença do controle interno ou até mesmo com um controle interno deficitário, poderá favorecer desvios de recursos públicos e uma gestão ineficiente, além de enfraquecer os resultados de valor público esperados pela sociedade. Controlar os atos administrativos e principalmente os gastos públicos de forma eficiente, autônoma e eficaz poderá proporcionar uma oferta maior dos serviços públicos voltados à população em diversas áreas, como saúde, educação, segurança,

\footnotetext{
${ }^{1}$ Doutor em Administração pelo PPGA/UFRN/UNIFACEX

${ }^{2}$ Especialista em Gestão Pública pela UNIFACEX

${ }^{3}$ Doutora em Administração pela FGV e professora da UFRN/PPGP/PPGA

${ }^{4}$ Doutor em Administração UFRN/Professor do PPGP/UFRN
} 
ação social e habitação. Nessa perspectiva, o controle interno também se enquadra como um instrumento de racionalização administrativa. Evidencia-se que há exigência legal para a implantação dos controles internos desde a Carta Magna de 1988.

A maioria dos gestores públicos municipais não reconhece a relevância do controle interno para uma gestão eficiente (MILESKI, 2003). O controle é interno, quando, segundo Mileski (2003, p.140), "[...] a própria Administração procede ao controle sobre seus atos, decorrendo do poder hierárquico que a organiza". Além de atender elementos de regramento formal, o controle interno no contexto municipal gera conforto gerencial e o respeito aos princípios da Administração Pública, mantendo o rigor à legalidade, mantendo o interesse público sempre a frente dos atos dos gestores da máquina pública. A adesão ao controle interno como uma ferramenta gerencialista possibilita reflexões ex ante a ação governamental, gerando um equilíbrio permanente entre rico x ação x consequências.

Neste cenário, muitos municípios do Rio Grande do Norte adotaram o Controle Interno em suas práticas de gestão. No entanto, não se sabe como essa prática vem contribuindo para melhorar o desempenho da ação governamental. Ao mesmo tempo em que os municípios vêm envidando esforços para implantação das atividades de controle há a necessidade de profissionais com expertise técnica à frente desses processos que tratam legalidade dos atos públicos e concomitante da obrigatoriedade de gerir de forma mais efetiva a maquina pública. Nesse diapasão compreender a visão desses profissionais sobre suas práticas de gestão âmbito das administrações locais assume relevância para a discussão sobre desempenho dos governos municipais.

Diante desse contexto emerge o seguinte problema de pesquisa: Quais as percepções dos controladores internos municip0ais acerca das suas práticas administrativas? Em decorrência, o objetivo do artigo é descrever a visão dos controllers municipais no Estado do Rio Grande do Norte sobre os atos administrativos no exercício do controle interno.

$\mathrm{O}$ artigo está estruturado em cinco seções, incluindo essa Introdução. Em seguida, aborda o controle interno destacando reflexões conceituais sobre o papel do controle interno ; em terceiro lugar, trata das questões metodológicas; a quarta seção discute os dados da pesquisa evidenciando a forma como os controladores percebem as suas práticas e, por fim tece considerações finais sobre a visão dos controles municipais.

\section{REFERENCIAL TEÓRICO}

\subsection{Controle interno - conceitos gerais}

A discussão a respeito do controle interno municipal, apesar de ecoar como um tema recente, tem como marco principal a Lei de $\mathrm{n}^{\circ} 4.320 / 1964$ que instituiu normas gerais de direito financeiro para elaboração e controle dos orçamentos e balanços da União, dos Estados, dos Municípios e do Distrito Federal e introduziu o controle interno e controle externo definindo as competências para o exercício dessas atividades.

Para Piscitelli (1998), os controles internos assumem os seguintes objetivos:

a) os aspectos eminentemente contábeis, formais e legais, revisando e/ou verificando as operações;

b) o aspecto da eficiência, que concerne aos meios empregados, verificando os recursos utilizados para a consecução dos objetivos da organização;

c) o aspecto da eficácia, verificando o produto, os programas e os fins perseguidos; e

d) o julgamento da própria administração, disponibilizando e tornando transparente uma prestação de contas de qualidade e os resultados. 
No aspecto contábil, formal e legal o controle interno atuará como um instrumento de padronização dos atos administrativos, fazendo com que a administração consiga identificar se sua contabilidade está equilibrada, se os fatos contábeis estão formalmente registrados e principalmente se estão seguindo as diretrizes emanadas pelas legislações vigentes. No aspecto da eficiência, o controle interno terá como observância a qualidade dos serviços prestados à população, sua principal finalidade. Como bem diz Meirelles (1993), os fins da Administração pública se resumem num único objetivo: o bem comum da coletividade administrada. Nesta perspectiva verificará ainda se os recursos utilizados para tais fins foram devidamente aplicados.

Para Portes (2012), a principal atribuição da atividade de controle interno é a fiscalização preventiva, concomitante e subsequente na ação da gestão pública, dirigindo, guiando e procedendo a correção de erros consciente e não conscientes dos atores governamentais, desperdícios e falhas que possam vir a comprometer a qualidade do resultado da gestão pública, tendo sua preocupação no contexto do meio (recursos) e do fim (efetividade).

O controle interno ainda irá aferir a eficácia das ações desenvolvidas pela administração pública para não só identificar se os serviços foram devidamente prestados, mas avaliar ainda a qualidade dos mesmos. Assim sendo, torna-se indispensável que o controle interno atue também no julgamento da própria administração, tornando-se transparente e acessível.

Segundo Meirelles (1993), o controle é a faculdade de vigilância, orientação e correção que um poder, órgão ou autoridade exerce sobre a conduta funcional do outro. Cruz e Glock (2003) vão dizer que o ato de controlar está diretamente ligado ao ato de planejar e visa garantir, através da aplicação dos recursos disponíveis, que algum resultado seja obtido.

Cook e Winkle (1979) colocam o conceito de controle interno, no âmbito contábil, como os procedimentos e os métodos que dizem respeito às operações de uma empresa e suas políticas, diretrizes e relatórios. Assim sendo, o controle interno ganha mais um viés de importância, na medida em que atua como órgão assessor no processo contábil da instituição, propiciando ao gestor, uma confiabilidade nos dados apresentados a respeito da situação das finanças municipais.

Para o comitê de procedimentos de Auditoria do Instituto Americano de Contadores Públicos:

[...] o controle interno compreende o plano de organização e todos os métodos e medidas adotadas na empresa para salvaguardar seus ativos, verificar a exatidão e fidelidade dos dados contábeis, desenvolver a eficiência nas operações e estimular o seguimento das políticas executivas prescritas.

Segundo Almeida (1996, p. 50), "o controle interno representa em uma organização o conjunto de procedimentos, métodos ou rotinas com os objetivos de proteger os ativos, produzir dados contábeis e ajudar a administração".

Vieira (2005, p.2) por sua vez, citará o controle interno "como o conjunto de recursos, métodos e processos, adotados pelas próprias gerências do setor público, com vista a impedir o erro, a fraude e a ineficiência". Agindo a priori, ou seja, antes dos atos serem praticados, o controle trás uma espécie de uma credibilidade ímpar, impedindo que erros, atos ilícitos e desvios de recursos públicos sejam evitados.

Para Peixe (2002), a finalidade do controle interno municipal é de dar consultoria e orientação permanente aos gestores nos diversos órgãos ligados ao governo municipal. Ou seja, deve ser compreendido como um campo de ação do Estado que tem como componente norteador a guarda da legalidade dos atos públicos resultando numa maior qualidade na efetividade governamental.

Para o Tribunal de Contas do Estado do Rio Grande do Norte, o controle interno no âmbito municipal objetiva: 
- Avaliar o cumprimento das metas previstas no plano, a execução dos programas de governo e dos orçamentos do município, com a observância da legislação e normas que orientam a atividade específica da unidade controlada, exercido diretamente pelos diversos níveis de chefia.

- Comprovar a legalidade e avaliar os resultados quanto à eficácia e eficiência, da gestão orçamentária, financeira e patrimonial nos órgãos e entidades da administração municipal;

- Controlar as operações de crédito, avais e garantias, bem como os direitos e haveres do município, e;

- $\quad$ Apoiar o controle externo, no exercício de sua missão institucional.

Os controles internos, de acordo com Cruz Silva (1999), no que concerne à forma do controle no momento do seu exercício e a fiscalização dos atos praticados pelo administrador podem ser a priori, concomitante ou a posteriori.

O controle a priori - palavra utilizada para fazer referência a um princípio anterior à experiência, são as ações de controle e avaliação que acontecem antes da ocorrência do evento ou fato que se pretende controlar com o intuito de prevenir ou impedir o sucesso de atos indesejáveis como erros, desperdícios ou irregularidades. Neste tipo de controle, o ato tem sua eficácia suspensa até ser submetido à análise e aprovação formal do órgão de controle.

No controle concomitante a verificação do ato é síncrono com a ação do administrador/gestor e, tem a finalidade de detectar erros, desperdícios ou irregularidades, no momento em que eles ocorrem, permitindo a adoção de medidas tempestivas de correção. Dessa forma, ajusta-se o desempenho ainda em andamento a fim de se conseguir o objetivo.

O controle a posteriori aprecia o ato, após sua prática, não permitindo qualquer ação corretiva relativamente ao desempenho completado. Uma vez detectado qualquer ato desfavorável, através de relatórios, caberá ao gestor implantar ações para correção de sua área ou organização no futuro.

A Constituição Federal é a lei fundamental e suprema de um Estado, que abrange normas respeitantes a formação dos poderes públicos, formas de governo, distribuição de competências, direitos e deveres do cidadão. Nesta perspectiva, a constituição seria entendida como síncrono de normas e princípios baseados em fatos históricos que objetiva orientar os atos do governo e dos cidadãos de um país, erguendo-se como a fonte legítima de todo ordenamento pátrio por ser a maior hierarquia normativa do país.

Conforme disposto no preâmbulo da própria constituição, esta busca instituir um Estado democrático, destinado a assegurar o exercício dos direitos sociais e individuais, a liberdade, a segurança, o bem-estar, o desenvolvimento, a igualdade e justiça como valores supremos de uma sociedade fraterna, pluralista e sem preconceitos, fundada na harmonia social e comprometida na ordem interna e internacional, com a solução prática de controvérsias.

Encontra-se nitidamente na constituição de 1988, traços que resguardam a ética administrativa, que segundo Ferraz (1992), chamou de princípios da administração pública. Voltado exclusivamente para a administração pública, os constituintes escreveram no art. 37, um capítulo sobre a administração pública, onde se destacam os princípios da: Legalidade, impessoalidade, moralidade, publicidade e eficiência.

Assim como os demais atores públicos a atuação do controle interno municipal, como unidade substancial vem a agregar na busca pelo atendimento dos princípios supracitados. Ao controlar o acompanhamento ou a execução da função administrativa, o órgão ou agente controlador deverá avaliar se na origem e no resultado dos atos administrativos os princípios constitucionais foram observados, avaliar se houve ou não causação de dano a terceiros, e, em caso positivo, impor o dever de reparação em um regime de responsabilidade objetiva, independente da natureza jurídica do agente direto. Nessa concepção, a finalidade do controle interno é assegurar que os órgãos atuem em consonância 
com os princípios constitucionais da legalidade, impessoalidade, moralidade, publicidade e eficiência.

Para Castro (2013), o controle interno-ou controle administrativo- representa a segurança do administrador. É fundamental, em primeiríssimo lugar, para o gestor público, porque este responde-com seus bens e sua reputação pelos atos que realiza ou delega a terceiros para praticar em seu nome. Deve, portanto, praticá-los com toda a segurança possível. O administrador precisa estabelecer controle em todos os níveis e de forma prévia para dar suporte a todos os seus atos decisórios.

Dentre os objetivos do controle interno é válido salientar que o principal deles, deve ser, mantê-los legítimos, ou seja, atender a todos os princípios constitucionais. Para Cavalheiro e Flores (2007), além de comprovar a legitimidade dos atos, devem estar sempre alinhados com os objetivos da organização.

O sistema de controle interno nasce, cresce se aprimora e pode vir a morrer junto com a instituição. Ele está dentro da própria instituição. Nessa acepção, é natural entender que os controles internos objetivam trabalhar os processos de forma eficiente e eficaz. O controle interno não é um fim, mas o meio. Toda entidade, independente de sua natureza jurídica, possui uma razão para existir, uma missão. Mesmo apresentando semelhanças, deve-se reconhecer que nenhuma instituição é completamente igual a outra. Logo, os controles internos nunca serão iguais uns aos outros, em que pese sempre haver objetivos e controles comuns.

Apesar de identificar através do posicionamento supracitado que os objetivos específicos do controle interno devem ser identificados ou desenvolvidos para cada atividade. Cavalheiro e Flores (2007, p.34), citam os seguintes objetivos gerais:

- $\quad$ A salvaguarda os ativos da organização;

- A confiabilidade nos registros contáveis;

- A eficiência e eficácia nas operações mediante a aplicação das melhores práticas gerenciais;

- A aderência as políticas;

- O cumprimento da lei e regulamentações, e;

- A mensuração dos indicadores de desempenho da organização, tanto em processos, na sua missão, como financeiros.

Fica evidente que o controle interno aborda a questão da eficiência como um eixo agregador de valor ao Gestor, trazendo ao longo das decisões rotineiras ou não o cuidado de respeitar a legalidade, atender aos objetivos públicos e alcançar a maximização da ação.

\subsection{O papel do controlador municipal}

O controlador municipal deve possuir uma visão sistêmica da gestão pública, relacionando-se com diferentes áreas técnicas a fim de obter um extenso conhecimento da administração pública.

Tendo como premissa a função do controlador, relacionando com os princípios básicos de controle descritos por Castro (2013) - planejar, organizar, dirigir e controlar, no que se refere ao ato de controlar, suas atividades acabam se caracterizando dentro das funções típicas do Estado, peculiar à natureza do ente político e que por este motivo não podem ser transferidas/delegadas a terceiros.

O controlador municipal deve estar amparado legalmente para o exercício do cargo, possuindo um perfil ilibado, habilitação e obter prerrogativas singulares que lhe possibilite o desempenho das funções de forma satisfatória.

Koliver (2005, p.27) opina a cerca da função do dirigente de controladoria: 
Exercer a função de controller requer conhecimento da atividade para poder executá-la adequadamente, requer interação e liderança para, assim, acompanhar a dinâmica do processo e da exata dimensão do negócio para o qual está recebendo total confiança. Vê-se que a atuação nessa área não constitui um modismo, tampouco se restringe a uma função específica, pois, para que um processo de gestão se complete, o profissional, por excelência deve ter visão ampla, atuando e controlando todas as áreas da organização. $\mathrm{O}$ ato de executar está baseado neste conjunto de elementos que se completam-liderança, fixação de objetivos, planejamento, implementação de ações, controle, avaliação de estoques, custos, preço de venda, consecução de metas, financeira-e, fundamentalmente, o controller, deve ter conhecimento de contabilidade, sabendo usá-la como instrumento de informação e de apoio.

Nesse mister, o controlador deve revestir-se da faculdade de possibilitar segurança à sociedade, ao chefe do poder executivo e demais poderes e órgãos fiscalizadores externos. Tais axiomas somente podem ser superados se o controlador, além de capacitado, tiver ainda condições técnicas e psicológicas necessárias.

A Resolução n 013/2013 do Tribunal de Contas do Estado do Rio Grande do Norte acrescenta ainda de forma sugestiva em seu Art. 10, parágrafo único:

Sugere-se que os integrantes do quadro de pessoal das Unidades de Controle Interno desempenhem as suas atividades em regime de dedicação exclusiva, devendo constar dentre eles, preferencialmente, no mínimo um profissional com formação acadêmica na área das Ciências Contábeis, da Administração, da Economia, do Direito ou da Gestão Pública.

As atribuições do controlador municipal embora sejam baseadas nas mesmas instruções normativas hierarquicamente superiores, poderão e deverão ser definidas pela legislação municipal. Apesar de não ter privilégios hierárquicos sobre as unidades administrativas que não estejam vinculadas expressamente à sua, algumas prerrogativas e garantias devem ser asseguradas ao controlador, como por exemplo, edição de instruções normativas e padronização de procedimentos técnicos. Com isso, a ênfase, lembram Moraes, Oliveira e Niwa (2013):

[...] do controle interno municipal, pois é por meio desse sistema que se pode fiscalizar o cumprimento das leis orçamentárias e da aplicação dos recursos recebidos da União e dos Estados. Quanto à transferência intergovernamental, uma vez ocorridas irregularidades quanto à aplicação dos recursos, imediatamente gera o cancelamento do convênio, devendo o município devolver o repasse recebido, ficando ainda impedido de celebrar novos convênios.(p.230).

Portanto, cabe à gestão municipal fiscalizar seus próprios atos (controle interno) e ações antes da fiscalização do controle externo e, de forma preventiva, corrigir falhas e sanar irregularidades a fim de evitar que os atos administrativos sejam apontados com desconfianças, sendo este o ponto que reside a fundamental importância do controle interno (p.231)

O controle interno municipal por se tratar de um órgão de staff, deve estar ligado diretamente ao gestor municipal, bem como aos demais gestores/secretários municipais. Nessa compreensão, unidades setoriais de controle interno separadamente por pastas estariam diretamente ligadas à unidade central de controle interno e ao Gabinete Civil do prefeito municipal.

O Tribunal de Contas do Estado do Rio Grande do Norte, no ano de 2013, se posicionou a respeito da criação, implantação, manutenção e coordenação dos sistemas de controle interno através da Resolução 
de $n^{\circ} 013$, de 05 de setembro daquele ano, onde nitidamente traz em seu art. $6^{\circ}$ que determina que "deverá ser atribuída a unidade organizacional especifica - unidade central de controle interno- que, criada no âmbito de cada poder por lei de iniciativa do seu competente titular, possua estrutura condizente com o porte e a complexidade do respectivo poder municipal".

\section{METODOLOGIA}

Esta pesquisa caracteriza-se por uma abordagem quantitativa, do tipo descritiva, pois objetiva apresentar a visão dos "controllers" municipais no âmbito do Rio Grande do Norte, sob a ótica de relevância do controle interno municipal. O universo de pesquisa são 88 municípios na pessoa dos profissionais "controllers" nomeados nos termos da legislação vigente (TCE, 2016), dos quais 36 responderam o instrumento. Assim, a amostra representa $41 \%$ do universo pesquisado. Este dado revela que 79 municípios não têm a atividade de controle interno formalmente constituída (já que o Estado do RN possui 167 prefeituras), o que evidencia sem muitas dificuldades um problema para a eficiência e eficácia da gestão pública que se dá sem parâmetros avaliativos.

O instrumento de coleta de dados foi um questionário estruturado em dois blocos: o primeiro traça o perfil sociodemográfico do profissional e o segundo aborda a atuação contábil, desempenho da eficiência, julgamento da própria administração sobre o controle, controle interno como instrumento de planejamento e o controle como forma de assinalar os erros objetivando suas correções, pois de acordo com os autores Piscitelli (1998), Meirelles (1993), Cruz e Glock (2003) e Fayol (1989) esses elementos estão associados à importância do controle interno no âmbito municipal na visão dos gestores. O bloco 2 foi composto por questões com Escala Likert de cinco pontos, variando de 1- concordo a 5-discordo totalmente.

A aplicabilidade do questionário deu-se por e-mail através de formulário criado no google docs, de 18 a 25 de Maio de 2016, havendo antes uma sensibilização por parte dos pesquisadores junto aos sujeitos quanto à importância da pesquisa por meio de envio de e-mails explicando a importância da pesquisa.

Os dados coletados foram tabulados e tratados com base no método de Análise Exploratória de Dados (AED), que utiliza a estatística descritiva, apresentando percentuais e frequência absoluta e relativa. Segundo Triola (2005), a AED é o processo de uso das ferramentas estatísticas (tais como gráficos, medidas de centro e de variação) para investigar um conjunto de dados, com o objetivo de compreender suas características importantes.

\section{ANÁLISE E DISCUSSÃO DOS DADOS}

\subsection{Perfil dos controllers municipais}

No Estado do Rio Grande do Norte, apenas 88 (do total de 167) dos municípios dispõem de controle interno municipal, o que leva à indagação sobre os motivos pelos quais os municípios ainda não dispõem de controles internos devidamente instituídos e em pleno funcionamento, como demanda a legislação vigente e recomenda o TCE/RN e também por quais motivos os órgãos de controle não cobram a efetivação da legislação.

Quando se analisa o perfil dos controllers, percebe-se que 69,5\% possuem até 40 anos de idade, $16,7 \%$ estão entre 40,1 a 50 anos e $13,9 \%$ tem idade superior a 50 anos, o que mostra uma maioria expressiva de controllers relativamente jovens. Notadamente, $55,6 \%$ dos entrevistados são do sexo 
feminino, enquanto 44,4\% são do sexo masculino. Indagados sobre a quantidade de tempo em que estão atuando na função de controle nos respectivos municípios, 83,3\% afirmam que possuem até 4 anos de atuação, enquanto $8,3 \%$ possuem de 4,1 a 8 anos e os outros $8,3 \%$ possuem acima de 8 anos de vivência nesta função.

Esse perfil de tempo de controle nos municípios revela que a maioria já tem tempo suficiente de trabalho com uma percepção mais acurada sobre as realidades em que laboram com compreensão da importância da atividade e dos elementos que facilitam ou dificultam a execução eficiente desse papel no âmbito municipal.

Quando se analisa o tempo de experiência na gestão pública, percebe-se que 52,8\% apresentam até 5 anos de experiência, 19,4\% detém de 5,1 a 10 anos, 25\% possuem entre 10,1 até 30 anos e 2,8\% possuem acima de 30 anos. Ou seja, quase $30 \%$ esta há mais de 5 anos em pleno exercício na gestão pública brasileira.

Em relação ao grau de instrução, 88,9 \% dos entrevistados possuem ensino superior completo, cursaram ou estão cursando pós-graduação, especialização ou mestrado/doutorado, enquanto 15,1\% possuem apenas o ensino médio completo ou ensino superior incompleto. Quanto à vinculação partidária, atualmente, $22,9 \%$ dos controllers estão vinculados a algum partido político, enquanto $77,1 \%$ não estão vinculados.

Indagados quanto à quantidade de agentes (empregados, servidores e etc.) que compõem o controle interno nos respectivos municípios, $36,1 \%$ responderam que o controle interno atua com apenas 1 servidor/funcionário, que seria o próprio controlador municipal, 52,84\% atuam com 2 ou 3, 2,8\% de 4 a 6 , $8,3 \%$ de 7 a 10 e nenhum dos municípios entrevistados atua com mais de 10 servidores na área de controle interno. Com isso, percebem-se o quanto ainda é insuficiente a quantidade servidores que atuam nesta área dentro da gestão pública do Estado do Rio Grande do Norte.

Identifica-se que antes de assumirem o papel de controle interno municipal, 52,8\% dos entrevistados não possuíam nenhuma capacitação na área de controle interno, enquanto 47,2\% já possuíam. Depreende-se, pois que foi a experiência prática o campo de aprendizagem por excelência de parte significativa dos controllers municipais. Quando interrogados sobre a frequência com que usavam ferramentas para interagir com os gestores municipais (informar, normatizar, notificar e etc.), os controllers responderam da seguinte forma: 8,3\% não utilizam ofícios, enquanto 91,6\% utilizam sempre ou raramente; $11,1 \%$ não utilizam e-mail, enquanto $88,8 \%$ utilizam sempre ou raramente; $47,2 \%$ não utilizam portarias, enquanto 52,7\% usam sempre ou raramente; $36,1 \%$ não utilizam resoluções, enquanto 63,8\% usam sempre ou raramente e com relação a utilização de memorandos, apenas 5,5\% não utilizam, enquanto $94,4 \%$ utilizam sempre ou raramente.

Percebe-se assim que a forma de comunicação mais usual é o memorando, classificado como a principal ferramenta de interação, comunicação entre os membros de controles interno e demais servidores municipais. Em seguida, traz-se a visão dos profissionais controllers sobre suas práticas administrativa nos municípios em que laboram.

\subsection{Percepção dos controllers}

Após apresentação do perfil dos controllers municipais será discutida a percepção destes sobre aspectos diversos do controle interno para a proteção da administração pública e a criação de condições para uma gestão municipal responsável, transparente e eficaz.

Os dados são apresentados em quadros, pelos quais se conjugaram variáveis de análise para possibilitar uma melhor compreensão. A Tabela 01 a seguir trata do primeiro bloco de variáveis 
associadas ao exercício do controle no município.

\section{Tabela 01}

\begin{tabular}{|c|c|c|c|c|c|}
\hline Variáveis & CT & C & I & D & DT \\
\hline $\begin{array}{l}\text { O controle interno objetiva atuar no aspecto contábil, } \\
\text { revisando e verificando as operações realizadas. }\end{array}$ & $30,50 \%$ & $50,00 \%$ & $8,30 \%$ & $5,50 \%$ & $5,50 \%$ \\
\hline $\begin{array}{l}\text { No desempenho das atividades do controle interno no } \\
\text { âmbito municipal, observa-se com frequência aferição } \\
\text { da eficiência dos atos. }\end{array}$ & $63,80 \%$ & $33,30 \%$ & $0,00 \%$ & $2,70 \%$ & $0,00 \%$ \\
\hline $\begin{array}{l}\text { Todas as ferramentas de controle (controle de metas, } \\
\text { apoio ao controle externo etc) disponíveis são usadas } \\
\text { pela gestão municipal, não havendo restrições de uso } \\
\text { por opção do gestor municipal. }\end{array}$ & $36,10 \%$ & $25,00 \%$ & $25,00 \%$ & $13,80 \%$ & $0,00 \%$ \\
\hline $\begin{array}{l}\text { A atuação do controle interno busca realizar o } \\
\text { julgamento da própria administração, para que a } \\
\text { mesma seja transparente e acessível. }\end{array}$ & $52,70 \%$ & $38,80 \%$ & $8,30 \%$ & $0,00 \%$ & $0,00 \%$ \\
\hline $\begin{array}{l}\text { O controle interno focaliza incansavelmente nos atos } \\
\text { e ações que buscam o planejamento dos atos públicos }\end{array}$ & $52,70 \%$ & $36,10 \%$ & $8,30 \%$ & $2,70 \%$ & $0,00 \%$ \\
\hline
\end{tabular}

Fonte: Pesquisa de campo, 2016.

Sobre a atuação do controle interno no aspecto contábil, para revisitar e verificar as operações realizadas, seguindo o pensamento de Piscitelli (1998), 80,5\% dos controllers afirmam concordar e concordar totalmente com a atuação nesse aspecto, enquanto 19,3\% responderam, indiferente, discordam ou discordam totalmente. Sob a ótica de Meirelles (1993), que afirma que os controles internos devem atentar para aferição da eficiência, os controllers em sua maioria, representada por $97,1 \%$ dos entrevistados concordam ou concordam totalmente com a perspectiva de que o controle interno deve seguir essa linha de raciocínio no seu agir, enquanto apenas 2,7 discordam desse pensamento.

Um fator importante a destacar, é que $61,1 \%$ dos controllers afirmam que a gestão municipal utiliza todas as ferramentas disponíveis sem nenhuma restrição de uso por opção do gestor municipal, enquanto 38,8\% responderam ser indiferentes, discordarem ou discordarem totalmente, o que mostra influência dos gestores municipais no desempenho das atividades dos controles internos., especialmente quando estes apontam o ferramental possível para o êxito de suas respectivas atividades. No que se refere à atuação de um controle interno como instrumento para realizar o julgamento da própria administração, tornando-a cada vez mais transparente e acessível, 91,5\% dos entrevistados concordam e concordam totalmente com Piscitelli (1998) enquanto apenas 8,3\% responderam indiferente.

Ao tratar de 'focalizar' o controle interno nos atos e ações que buscam o planejamento dos atos públicos segundo o prisma de Cruz e Glock (2003), 88,8 \% responderam concordar ou concordar totalmente, enquanto $11 \%$ responderam indiferente ou discordam dessa asserção. Isso denota que a função do controle está em convergência com a ideia de um composto de ação governamental suportada pela concepção do planejamento. Isso significa que os controles internos municipais, não se prendem a apenas analisarem os atos já praticados pela administração, mas participam ativamente do planejamento para que não seja necessário posteriormente atuarem na identificação de equívocos no próprio planejamento.

A Tabela 2 a seguir trata do segundo bloco de variáveis associadas ao exercício do controle no município. 


\section{Tabela 02}

\section{Variáveis}

Independentemente do tamanho, todas as organizações devem identificar, capturar e comunicar informações pertinentes em tempo hábil permitindo as pessoas a realização de atividade e cumprimento de suas responsabilidades.

A gestão municipal converge, plenamente, com a manutenção plena de um modelo de 'controle' eficiente.

Em nossa rotina administrativa o controle interno ao identificar equívocos, vícios, erros e falhas assinala imediatamente para que possam ser reparados.

Em nossas atividades desempenhamos a função de consultoria aos demais órgãos ligados ao governo municipal.

No meu município o controle a posteriori aprecia o ato após a sua consumação, não permite qualquer ação corretiva relativamente, ao desempenho completado, embora funcione como um mecanismo motivador, uma vez que uma variação desfavorável, informada por meio de relatórios gerenciais, leva o gestor a implementar ações para corrigir o desempenho de sua área ou da organização no futuro.

\begin{tabular}{|c|c|c|c|c|}
\hline \multicolumn{5}{|c|}{ Escala } \\
\hline CT & C & I & D & DT \\
\hline $27,00 \%$ & $52,70 \%$ & $13,80 \%$ & $5,50 \%$ & $0,00 \%$ \\
\hline $27,70 \%$ & $52,70 \%$ & $13,80 \%$ & $5,50 \%$ & $0,00 \%$ \\
\hline $55,50 \%$ & $41,60 \%$ & $2,70 \%$ & $0,00 \%$ & $0,00 \%$ \\
\hline $33,30 \%$ & $58,30 \%$ & $2,70 \%$ & $5,50 \%$ & $0,00 \%$ \\
\hline $22,20 \%$ & $44,40 \%$ & $11,10 \%$ & $16,60 \%$ & $5,50 \%$ \\
\hline
\end{tabular}

Fonte: Pesquisa de campo, 2016.

Há uma grande concordância no que diz respeito à ideia de que as organizações devem identificar, capturar e comunicar informações pertinentes em tempo hábil, permitindo as pessoas a realização de atividades e cumprimento de suas responsabilidades, pois $80,4 \%$ dos controllers concordam ou concordam totalmente com essa afirmativa, enquanto 19,3\% optaram por responder indiferente ou discordam. Quando indagados sobre a convergência total da gestão municipal para manutenção plena de um modelo de 'controle' eficiente, $80,4 \%$ concordam e concordam plenamente, o que leva a crer que há certa mobilização para que as ações do controle interno não sofram nenhuma influência de terceiros, enquanto $19,3 \%$ responderam indiferentes ou discordaram.

Nas rotinas administrativas dos controles internos do Rio Grande do Norte, ao identificar equívocos, vícios, erros e falhas, 96,7\% dos entrevistados concordam que devem ser assinalados para que possam ser reparados, corroborando com a ideia de Fayol, (1989), que traz justamente essa ideia de que uma das funções principais dos controles internos, seria justamente apontar os equívocos ou atos que poderiam trazer riscos à administração, para que as medidas de correção possam ser tomadas; 91,6 \% dos controllers, concordam ou concordam plenamente com a ideia de que o controle interno desempenha uma função de consultoria aos demais órgãos ligados ao governo municipal, não atentando-se somente aos atos do poder executivo, mas à administração como um todo, haja vista que mesmo que ocorram individualmente, os atos públicos tendem a impactar toda a gestão administrativa. Essa função evidencia que os controles podem servir de área consultiva, o que ensejaria menos erros e imperícias dos atores municipais.

Corroborando com Cruz Silva (1999) um percentual de 66,6\% dos entrevistados compactua, concordando e concordando plenamente com a concepção de que o controle a posteriori aprecia o ato após 
sua consumação, não permitindo qualquer ação corretiva relativamente ao desempenho completado, embora funcione como mecanismo motivador, uma vez que uma variação desfavorável, informada por meio de relatórios gerenciais, pode propiciar ao gestor a implementação de medidas corretivas, corrigindo o desempenho de sua área ou da organização como um todo no futuro, enquanto 33,2\% optaram por responder indiferente, discordam ou discordam totalmente.

A seguir a Tabela 03 mostra o terceiro bloco de variáveis associadas ao exercício do controle no município.

\section{Tabela 03}

\begin{tabular}{|c|c|c|c|c|c|}
\hline Variáveis & CT & $\mathbf{C}$ & I & D & DT \\
\hline $\begin{array}{l}\text { Possuímos um ótimo sistema de monitoramento dos } \\
\text { atos da administração pública municipal }\end{array}$ & $8,30 \%$ & $27,70 \%$ & $22,20 \%$ & $27,70 \%$ & $13,80 \%$ \\
\hline $\begin{array}{l}\text { Há um comprometimento } \quad \text { total dos } \\
\text { auxiliares(secretários municipais e demais autores) } \\
\text { quando ao respeito e incorporação do controle em sua } \\
\text { prática de gestão descentralizada. }\end{array}$ & $19,40 \%$ & $25,00 \%$ & $22,20 \%$ & $19,40 \%$ & $13,80 \%$ \\
\hline $\begin{array}{l}\text { O controle interno municipal busca meios de sempre } \\
\text { normatizar os atos administrativos. }\end{array}$ & $38,80 \%$ & $44,40 \%$ & $11,10 \%$ & $2,70 \%$ & $2,70 \%$ \\
\hline $\begin{array}{l}\text { A atuação do controle interno municipal, acontece: a } \\
\text { priori, concomitantemente e a posteriori dando a ideia } \\
\text { de um ciclo que auxilia os atos da gestão. }\end{array}$ & $33,30 \%$ & $44,40 \%$ & $8,30 \%$ & $2,70 \%$ & $8,30 \%$ \\
\hline $\begin{array}{l}\text { As ações desempenhadas são pautadas nos princípios } \\
\text { da legalidade, impessoalidade, moralidade, publicidade } \\
\text { e eficiência, conforme o Art. } 37 \text { da CF de } 88 \text {. }\end{array}$ & $66,60 \%$ & $22,20 \%$ & $8,30 \%$ & $0,00 \%$ & $2,70 \%$ \\
\hline $\begin{array}{l}\text { Há uma prática de estimulo e respeito as políticas } \\
\text { traçadas pelo governo por parte do controle interno } \\
\text { municipal. }\end{array}$ & $30,50 \%$ & $52,70 \%$ & $11,10 \%$ & $2,70 \%$ & $2,70 \%$ \\
\hline
\end{tabular}

Fonte: Pesquisa de campo, 2016.

É válido salientar que ao serem questionados sobre a capacidade do controle interno municipal ter um ótimo sistema de monitoramento doa atos da administração municipal, 63,8\% responderam indiferente, discordaram ou discordaram totalmente. Nessa perspectiva, pode-se analisar que os próprios controllers municipais, identificam que o sistema de monitoramento dos atos das próprias administração não acompanham a necessidade de veracidade e qualidade das informações necessárias.

Ainda neste aspecto de relevância, pode-se perceber que 55,4\% discordam, discordam totalmente ou responderam indiferente no que tange ao comprometimento por parte dos secretários municipais e demais autores quanto ao respeito e incorporação do controle em sua prática de gestão descentralizada, ao tempo que $44,4 \%$ concordam ou concordam plenamente.

Isso significa que não há um comprometimento esperado no que se refere à colaboração por parte dos agentes públicos que desempenham funções relevantes e assumem cargos de confiança no município para que as ações de controle interno sejam desempenhadas de forma plena.

A busca pela normatização dos atos públicos pelos controles internos municipais no âmbito do Rio Grande do Norte alcança 83,2\% dos controladores municipais que concordam ou concordam plenamente, enquanto $16,5 \%$ optaram indiferente, discordam ou discordam totalmente.

Para $77,7 \%$ dos entrevistados, concordam ou concordam totalmente que as atuações dos controles internos acontecem a priori, concomitantemente e a posteriori, enquanto 19,3\% responderam indiferente, 
discordam ou discordam plenamente. Ou seja, na maioria dos casos, o controle interno municipal, por motivos desconhecidos, não conseguem atuar nessas três instâncias.

Quando analisado o desempenho do controle interno sob a ótica constitucional, 88,8\% dos controllers afirmam, concordando e concordando plenamente que as ações são pautadas nos princípios da legalidade, impessoalidade, moralidade, publicidade e eficiência conforme disposto o Art. 37 da CF de 88, enquanto $11 \%$ optaram por responder indiferente ou discordam totalmente. Pode-se identificar que há por parte de $83,2 \%$ dos controllers um estímulo e respeito às práticas traçadas pelo governo, enquanto $11,1 \%$ responderam por indiferente e 5,4\% discordam ou discordam totalmente. Isso demonstra que a grande maioria dos controles internos, dentro de suas ações, procura contribuir para o alcance das metas traçadas pelo governo municipal.

A seguir a Tabela 04 mostra o último bloco de variáveis associadas ao exercício do controle no município.

\section{Tabela 04}

\begin{tabular}{|c|c|c|c|c|c|}
\hline Variáveis & CT & $\mathbf{C}$ & I & D & DT \\
\hline $\begin{array}{l}\text { Dentre tantas finalidades, o controle interno objetiva } \\
\text { de forma substancial a inibição a corrupção. }\end{array}$ & $55,50 \%$ & $38,80 \%$ & $2,70 \%$ & $2,70 \%$ & $0,00 \%$ \\
\hline $\begin{array}{l}\text { O controle interno municipal por se tratar de um } \\
\text { órgão no qual apresenta um nível de staff, a título de } \\
\text { assessoramento, este está ligado diretamente ao } \\
\text { gestor municipal, bem como aos demais secretários } \\
\text { municipais, cujas orientações exaradas são sempre } \\
\text { cumpridas pelos gestores. }\end{array}$ & $47,20 \%$ & $44,40 \%$ & $5,50 \%$ & $2,70 \%$ & $0,00 \%$ \\
\hline $\begin{array}{l}\text { A identificação e análise de riscos internos e } \\
\text { externos são relevantes ao alcance dos objetivos do } \\
\text { município, portanto, nesta avaliação, devem ser } \\
\text { observados: A severidade, a frequência com que } \\
\text { ocorrem e o grau de impacto, determinando a partir } \\
\text { dai, como a organização administrará tais riscos, por } \\
\text { isso essa atividade é plenamente incorporada na } \\
\text { prática do controle na prefeitura }\end{array}$ & $41,90 \%$ & $36,10 \%$ & $19,40 \%$ & $2,70 \%$ & $0,00 \%$ \\
\hline $\begin{array}{l}\text { A lei municipal que cria (regulamenta) o controle } \\
\text { interno tem como base integral os conceitos do Art. } \\
74 \text { da CF de } 88 \text {. }\end{array}$ & $47,20 \%$ & $52,70 \%$ & $0,00 \%$ & $0,00 \%$ & $0,00 \%$ \\
\hline $\begin{array}{l}\text { As ações de controle interno municipal são } \\
\text { aprovadas pelo administrador municipal, sendo } \\
\text { reconhecidas como fundamental para sua segurança } \\
\text { nos atos públicos. }\end{array}$ & $44,40 \%$ & $41,60 \%$ & $13,80 \%$ & $0,00 \%$ & $0,00 \%$ \\
\hline $\begin{array}{l}\text { A lei municipal que cria/regulamenta o controle } \\
\text { interno, segue completamente as orientações } \\
\text { emanadas pela resolução } 013 / 2013 \text { do Tribunal de } \\
\text { Contas do Estado do Rio Grande do Norte. }\end{array}$ & $47,20 \%$ & $41,60 \%$ & $2,70 \%$ & $2,70 \%$ & $5,50 \%$ \\
\hline
\end{tabular}

Fonte: Pesquisa de campo, 2016.

No meio de diversas atividades afins que abrangem a atuação do controle interno municipal a inibição às práticas de corrupção aparece como uma das mais citadas pelos entrevistados, haja vista que 94,3\% concordam e concordam totalmente que essa ação é um objetivo substancial do controle interno em seus municípios, contra apenas a 2,7\% que optaram por indiferente e $2,7 \%$ que discordaram. 
Para Peixe (2002), os controles internos por estarem em um nível de staff, deveriam assessorar diretamente o gestor municipal, bem como os demais atores municipais, cujas orientações exaradas deveriam ser seguidas/cumpridas por todos que compõem o poder decisório governamental. Essa postura é constatada na pesquisa, pois se pode observar que quase $92 \%$ dos entrevistados concordam e concordam plenamente com esta posição, 5,5\% optaram por indiferente e 2,7\% discordaram. O que leva a crer que nem sempre as orientações são seguidas por tais gestores. Partindo do pressuposto de que a identificação dos riscos internos e externos são relevantes para o alcance dos objetivos do município, 77,7\% dos entrevistados concordam e concordam plenamente que essa avaliação deve observar a severidade, frequência com que acontece e o grau de impacto determinado a partir dai como a organização administrará tais riscos, enquanto $22,1 \%$ responderam indiferente ou discordaram.

$\mathrm{Na}$ maioria dos municípios que compõe o universo pesquisado, $100 \%$ dos entrevistados concordam ou concordam completamente com a ideia de que a lei municipal que cria, regulamenta o controle interno municipal, teve como base legal os conceitos do Art. 74 da CF de 88, o que permite identificar que todas elas são constitucionais e obedecem os preceitos da Lei máxima do país.

Com relação ao cumprimento das diretrizes emanadas pelo Tribunal de Contas do Estado do Rio Grande do Norte, através da Resolução ${ }^{\circ}$ 013/2013, 88,8\% dos controllers responderam concordando e concordando totalmente, que tais leis municipais, estão em plena consonância com a resolução supracitada, enquanto $10,9 \%$ optaram por indiferente, discordam ou discordam totalmente.

As ações desempenhadas pelos controles internos municipais são aprovadas por $86 \%$ dos gestores municipais, onde estes as reconhecem como fundamental para sua segurança nos atos públicos enquanto que 13,8\% responderam indiferentes. Tem-se afim que na pesquisa ratificam-se ainda que o cenário para o controle interno tem espaço para ser acatado pela gestão de uma melhor forma, assim como a que dispõe desse ferramental, já reconhece nela uma melhor estruturação em suas ações governamentais.

\section{CONCLUSÃO}

Este artigo objetivou identificar a percepção dos controladores internos municipais que atuam nos municípios do Estado do Rio Grande do Norte acerca das suas práticas administrativas. Assim, constatouse que o controle interno municipal ainda não é visto e tratado pelos gestores dos municípios como um relevante órgão para propiciar ao próprio gestor municipal e seus auxiliares, atos pautados nas convicções da legislação vigente, bem como na eficiência, eficácia e porque não dizer terem seus atos reconhecidos como de qualidade no contexto de interesse público, afastados de qualquer conteúdo ou forma nefasta ou ilegal.

Poucos municípios no Rio Grande do Norte dispõem de controle interno devidamente instituído, absoluto, estruturado no ponto de vista físico e técnico, mínimo para um melhor desempenho da função. Mesmo de forma mediana, aos poucos, sob forte influência e apoio do Tribunal de Contas do Estado do Rio Grande do Norte, o tema 'controle interno municipal' vem cada vez mais sendo incluído nas agendas dos gestores municipais. Porém, de um modo um tanto quanto confuso, haja vista que ao criar os controles municipais, os gestores buscam apenas cumprir a exigências e orientações sem ao menos se deterem na qualidade do desempenho dessas atividades.

A visão dos respondentes de uma forma geral é que embora haja por parte dos mesmos um interesse significativo em desenvolver as atividades de controle em toda sua magnitude, tal anseio ainda não é uma realidade no Estado do Rio Grande do Norte, pelos motivos que foram citados, o que leva a crer que embora a presença dos controles internos municipais venha se tornando presente cada vez mais, a 
forma ao qual os mesmos atuam distancia-se ainda do ponto de vista esperado pelos tribunais de contas e demais órgãos fiscalizadores.

Pode-se elencar como limites ou dificuldades na pesquisa, a não coleta de dados em todos os municípios do Rio Grande do Norte, por incompatibilidade de horários ou até mesmo pela ausência de municípios com a atividade de controle interno instituida. Outro fator dificultador, foi o não retorno das respostas no instrumento de coleta por parte dos pesquisados, uma vez que alguns controllers não se interessaram em contribuir com a pesquisa.

Dentre os futuros estudos, faz-se necessário uma análise minuciosa que leve em consideração os possíveis motivos que levam os gestores públicos municipais a não demonstrarem interesse e enfatizarem nos seus mandatos a consolidação de controles internos municipais cada vez mais elaborados e em pleno funcionamento. Outra pesquisa futura pode tentar compreender a relação dos controles com as instâncias descentralizadas no próprio município, identificando como se dá essa relação institucional.

\section{REFERÊNCIAS}

ALMEIDA, M. C. Auditoria: um moderno curso e complemento. São Paulo: Atlas, 1996.

BRASIL. Lei nº 4.320, 17 de março de 1964. Estatui Normas Gerais de Direito Financeiro para elaboração e controle dos orçamentos e balanços da União, dos Estados, dos Municípios e do Distrito Federal. Diário Oficial da União, 23 mar. 1964. Disponível em: <http://www.planalto.gov.br/ccivil_03/leis/L4320.htm>.

CASTRO, D. P. Auditoria, contabilidade e controle interno no setor público. São Paulo: Atlas, 2013.

CAVALHEIRO, J. B.; FLORES, P. C. A organização do sistema de controle interno municipal. Porto Alegre, 2007.

COOK, J.W.; WINKLE, G.M. Auditoria: Filosofia e técnica. São Paulo: Saraiva, 1979.

CRUZ SILVA, F. C. da. Controle e reforma administrativa no Brasil. Salvador, 1999. 90p.

CRUZ, F. da; GLOCK, J. O. Controle interno nos municípios. São Paulo: Atlas, 2003.

FAYOL, H. Administração industrial e geral: previsão, organização, comando, coordenação, controle. 10 ed. São Paulo: Atlas, 1989.

FERRAZ, S. O controle da administração pública na constituição de 1988. Revista de direito administrativo, Rio de Janeiro, n.188, abr./jun., p. 64-73, 1992.

KOLIVER, O. A contabilidade e a controladoria, tema atual e de alta relevância para a profissão contábil. Porto Alegre: CRCRS, 2005. 40p.

MORAES, M.A.de; OLIVEIRA, A.G.de ; NIWA, T.H. Controle interno como instrumento de planejamento, organização e transparência na administração pública municipal: o caso do município de Guarei/SP. Revista Controle: Doutrina e Artigos. V.11. N. 2, 2013.

MEIRELLES, H. L. Direito municipal brasileiro. São Paulo: Malheiros, 1993.

MILESKI, H. S. O controle da gestão pública. Departamento do Tesouro Nacional. Instrução normativa n 16. 20-12-1991. São Paulo: Revista dos tribunais, 2003.

MOREIRA, M. M. O controle Interno como paradigma da administração pública gerencial. Arcos, Minas Gerais, 2004. 
PEIXE, B.C.S.. Finanças Públicas: controladoria governamental. Curitiba: Juruá, 2002.

PORTES,D.. Administração Pública e organizações da sociedade civil de interesse público: controle no Estado de Minas Gerais. /Daniela Duarte Portes.-2012. Disponível em:http://www.mestradoemgsedl.com.br/wp-content/uploads/2016/12/DANIELADUARTE-PORTES.pdf

PISCITELLI, R. O controle interno na administração pública federal brasileira. Brasília, ESAF, 1998.

TRIBUNAL DE CONTAS DO ESTADO DO RIO GRANDE DO NORTE. Resolução nº 013/2013, 05 de Setembro de 2013. Dispõe sobre a criação, implantação, manutenção e coordenação de Sistemas de Controle Interno nos Poderes Executivo e Legislativo Municipais e dá outras providências. Diário eletrônico do TCE/RN, 06 set. 2013.

TRIBUNAL DE CONTAS. Manual de auditoria e de procedimento. v. 1, Lisboa, 1999.

TRIOLA, M. F.. Introdução à estatística. 9 ed.. Rio de Janeiro: LTC, 2005. 
